\title{
Simultaneous estimation of Esomeprazole and Tadalafil in pharmaceutical formulations using High Performance Liquid Chromatography
}

\author{
Mohammed Hamad ${ }^{1}$, Ahmed Al-Sharqawi ${ }^{2}$, Wael Abu Dayyih ${ }^{2 *}$, Eyad Mallah ${ }^{2}$, Tawfiq Arafat ${ }^{2}$ \\ ${ }^{1}$ Department of Basic Sciences, Collage of Sciences and Health Professions, King Saud Bin Abdulaziz University for Health Scien ces - Jeddah, Saudi \\ Arabia. ${ }^{2}$ Department of Pharmaceutical Medicinal Chemistry and Pharmacognosy, Faculty of Pharmacy and Medical Sciences - University of Petra \\ /Amman- Jordan.
}

\section{ARTICLE INFO}

Article history:

Received on: 05/01/2016

Revised on: 05/02/2016

Accepted on: 23/02/2016

Available online: 30/04/2016

Key words:

Esomeprazole, HPLC,

Tadalafil, Validation,

pharmaceutical formulation.

\begin{abstract}
An easily, specific, precise, and accurate reversed-phase HPLC method was developed and validated for simultaneous estimation of esomeprazole $\left(\mathrm{Nexium}^{\circledR}\right)$ and tadalafil $\left(\mathrm{Cialis}^{\circledR}\right)$ in pharmaceutical formulation. The separation was achieved by using Hypersil BDS C18 column $(250 \mathrm{~mm} \times 4.6 \mathrm{~mm} ; 5.0 \mu \mathrm{m})$ and acetonitrile: 0.05 $\mathrm{M}$ potassium dihydrogen phosphate buffer at $\mathrm{pH} 6$ adjusted with phosphoric acid as a mobile phase at a flow rate of $1 \mathrm{~mL} / \mathrm{min}$. Detection was carried out at wavelength $285 \mathrm{~nm}$. The retention time of esomeprazole and tadalafil were $3.1,3.7 \mathrm{~min}$, respectively. The linearity was established over the concentration ranges of 60 $180 \mu \mathrm{g} / \mathrm{mL}$ and $40-120 \mu \mathrm{g} / \mathrm{mL}$ with correlation coefficients 0.9998 and 0.9996 for esomeprazole and tadalafil, respectively. The mean recoveries were found to be in the ranges of $98-102 \%$ for esomeprazole and tadalafil. The proposed method has been validated as per ICH guidelines and successfully applied to the simultaneous estimation of esomeprazole and tadalafil in pharmaceutical formulation.
\end{abstract}

\section{INTRODUCTION}

\section{Esomeprazole}

It is the S-enantiomer of omeprazole and has the chemical formula $\mathrm{C} 17 \mathrm{H} 19 \mathrm{~N} 3 \mathrm{O} 3 \mathrm{~S}$.and has the IUPAC name 5methoxy-2-[(R)-[(4-methoxy-3,5-dimethylpyridin-2-yl) methane] sulfinyl]-1H-1,3-benzodiazole with an average weight of 345.416 $\mathrm{g} / \mathrm{mol}$. The chemical structure is shown in Figure (1) (Lind et al., 2000). Esomeprazole is a proton pump inhibitor (PPI) that suppresses gastric acid secretion by specific inhibition of the $\mathrm{H}+/ \mathrm{K}+$ ATPase in the gastric parietal cell. By acting specifically on the proton pump, esomeprazole blocks the final step in acid production, thus reducing gastric acidity (Scott et al., 2002).

\section{* Corresponding Author}

Wael Abu Dayyih, Department of Pharmaceutical Medicinal Chemistry and Pharmacognosy, Faculty of Pharmacy and Medical Sciences -

University of Petra /Amman-Jordan. Email: wabudayyih[at]uop.edu.jo
Esomeprazole is indicated for the treatment of acid-reflux disorders (GERD), peptic ulcer disease, Helicobacter Pylori eradication, and prevention of gastroinetestinal bleeds with NSAID use (Johnson, 2003).

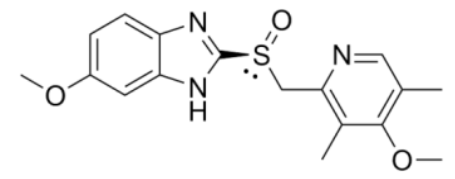

Fig. 1: Chemical structure of esomeprazole.

Esomeprazole, used as part of triple therapy, is indicated for the eradication of $H$. pylori to reduce the risk of duodenal ulcer recurrence (McColl et al., 1998).

Eradication of $H$. pylori is achieved by combination of esomeprazole with antibiotics, clarithromycin, and amoxicillin (or metronidazole) which is the major factor in duodenal and peptic ulcers (Fischbach and Evans, 2007). 


\section{Tadalafil}

It has the molecular formula $\mathrm{C} 22 \mathrm{H} 19 \mathrm{~N} 3 \mathrm{O} 4$ with a molar mass of $389.404 \mathrm{~g} / \mathrm{mol}$ (Daugan et al., 2003). Tadalafil chemical structure is shown in figure (2). Tadalafil is a selective phosphodiesterase 5 inhibitor used to treat erectile dysfunction (impotence; inability to get or keep an erection) and the symptoms of benign prostatic hyperplasia (an enlarged prostate) which include difficulty urinating (hesitation, dribbling, weak stream, and incomplete bladder emptying), painful urination, and urinary frequency and urgency in adult men. Additionally tadalafil is used to improve the ability to exercise in people with pulmonary arterial hypertension (high blood pressure in the vessels carrying blood to the lungs, causing shortness of breath, dizziness, and tiredness) (Allen et al., 2004). Application of validated analytical method to guarantee that the performance characteristics of the method meet the requirements for the intended analytical application and are capable of giving reproducible and reliable results (Taverniers et al., 2004; USP , 2006; Rafferty et al., 2010; Snyder et al., 2010; Abu Dayyih et al., 2012; 2013). High performance liquid chromatography (HPLC) is a separation technique that involves in separation, evaluation and validation of drugs in different solutions and according to international conference of harmonization guideline (ICH), FDA and USP the operation of HPLC must be validated and maintained cleaned.

Several methods for validation and measurement of esomeprazole alone or in combination with other drugs were used in different drug formulations, plasma and other fluids such as; HPLC (Onal and Oztunç, 2006; Dilip et al., 2011; Kumar et al., 2011; Jain et al., 2011; Nalwade et al., 2012), UVSpectrophotometery (Patil Shamkant et al., 2009) and LC-MS/MS (Hultman et al., 2007). Also, as per literature there are many methods used to validate of tadalafil alone or in combined with other drugs in drug formulation, plasma and other fluids; HPLC (Farthing et al., 2010; Kamepalli Sujana et al., 2012; Rajpar et al., 2012; Nagaraju et al., 2012; Samala et al., 2013).

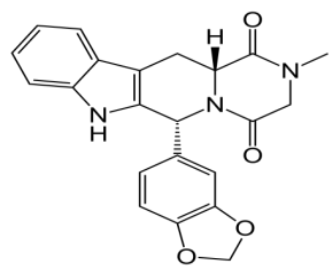

Fig. 2: Chemical structure of Tadalafil.

Many methods indicated that HPLC was a consistent way for the evaluation of esomeprazole and tadalafil separately in several samples, such as pharmaceutical formulations, drinks, plasma and other biological fluids, and it can be used to study the pharmacokinetics parameters of these drugs (Onal and Oztunç, 2006; Farthing ; et al., 2010; Dilip et al., 2011; Kumar et al., 2011; Jain et al., 2011; Nalwade et al., 2012; Kamepalli Sujana et al., 2012; Rajpar et al., 2012; Nagaraju et al., 2012; Samala et al., 2013). Up to date literature survey indicate no method for simultaneous estimation of both esomeprazole and tadalafil in pharmaceutical formulation. Current study aimed to develop and validate simple, accurate, precise, and cost effective HPLC method for simultaneous estimation of esomeprazole and tadalafil in pharmaceutical formulations.

\section{MATERIALS AND METHODS}

\section{Apparatus}

Thermo (HPLC): (spectra system, AS 3000) pump and degasser connected to a UV 3000. Injections were performed using auto sampler type (spectra system), $25 \mu \mathrm{L}$ sample loop and Chromo-Quest Computing integrator software. A Hypersil BDS C18 with $5.0 \mu \mathrm{m}$ particle size $(250 \mathrm{~mm} \times 4.6 \mathrm{~mm})$ column. RAYleigh (UV-Visible-spectrophotometer) UV-2601. Bathsonicator Crest model-175T (Ultra Sonics CORP.), Sartorius balance BP 2215, Sartorius PH meter (Professional meter PP-25), centrifuge (eppendorf 5417C).

\section{Selection of Detection Wavelength}

UV-VIS scan (250-500 nm) was applied for each solution of esomeprazole and tadalafil. A maximum absorbance was observed for each drug in a range of 281-287 nm. A wavelength at $285 \mathrm{~nm}$ was selected for HPLC analysis.

\section{Buffer Preparation}

The buffer solution was prepared by dissolving about $7 \mathrm{~g}$ of potassium dihydrogen phosphate in $1000 \mathrm{~mL}$ of HPLC-grade water. A concentration of $0.05 \mathrm{M}$ was obtained.

\section{Mobile Phase Preparation}

$400 \mathrm{~mL}$ of buffer solution were mixed with $600 \mathrm{~mL}$ of acetonitrile, and the $\mathrm{pH}$ was adjusted to $6.00 \pm 0.05$ using phosphoric acid. The mobile phase was filtered through a $0.45 \mu \mathrm{m}$ membrane filter and degassed by sonication.

\section{Preparation of Standards Solutions}

A stock solution of each of esomeprazole and tadalafil was prepared by dissolving about 60 and $40 \mathrm{mg}$ (highly pure material >99.7\%), respectively in $50.0 \mathrm{~mL}$ volumetric flask of mobile phase. $5.0 \mathrm{~mL}$ from each stock solution were diluted into $50.0 \mathrm{~mL}$ mobile phase. Concentrations of about 120 and $80 \mu \mathrm{g} / \mathrm{mL}$ were obtained, respectively.

\section{Preparation of Samples Solutions}

A sample solution was prepared by dissolving about $860 \mathrm{mg}$ of $\mathrm{Nexium}^{\circledR}$ equals to $60 \mathrm{mg}$ of the active ingredient esomeprazole and $718 \mathrm{mg}$ Cialis ${ }^{\circledR}$ equals to $40 \mathrm{mg}$ of the active ingredient tadalafil from each finished product in $50.0 \mathrm{~mL}$ of mobile phase (stock solution). $5.0 \mathrm{~mL}$ from each stock solution were diluted up to $50.0 \mathrm{ml}$ using the mobile phase. Consequently, concentrations of about 120 and $80 \mu \mathrm{g} / \mathrm{mL}$ were obtained, respectively for esomeprazole and tadalafil. 


\section{Preparation of Placebo Solution}

The placebo was prepared in laboratory based on the most common excipients in the market, namely (Starch 15\%, Lactose $15 \%$, Mg-sterate $5 \%$ and Avicel $65 \%$ ) without any activeingredients. A placebo solution was prepared by addition of about $700 \mathrm{mg}$ in $50.0 \mathrm{~mL}$ mobile phase.

\section{Chromatographic Conditions}

Chromatographic conditions are listed in table (1).

Table 1: Chromatographic conditions.

\begin{tabular}{cl}
\hline Parameters & \multicolumn{1}{c}{ Conditions } \\
\hline Column Type & A Hypersil BDS C18 with $5.0 \mu \mathrm{m}$ particle size \\
& $(250 \mathrm{~mm} \times 4.6 \mathrm{~mm})$ \\
Mobile Phase & A mixture of $60 \%$ acetonitrile: $40 \%$ buffer \\
& $\mathrm{pH}: 6.00$ \\
Flow Rate & $1.0 \mathrm{~mL} / \mathrm{min}$ \\
Wave length & $285 \mathrm{~nm}$ \\
Injection volume & $10 \mu \mathrm{L}$ \\
Expected RT & Esomeprazole : $3.1 \mathrm{~min}$. Tadalafil : $3.7 \mathrm{~min}$ \\
\hline
\end{tabular}

\section{System Precision Standard Test Preparation}

One homogenous sample solution of the standard drugs esomeprazole $60 \mathrm{mg}$ and $40 \mathrm{mg}$ tadalafil was prepared by weighing and dissolving them in $50 \mathrm{~mL}$ of mobile phase solution as solvent and injected repeatedly (6 injections) in this test the data observed in table (2).

Table 2: System Precision Test Results.

\begin{tabular}{lcc}
\hline \multicolumn{1}{c}{ Parameters } & Esomeprazole & Tadalafil \\
\hline Concentration \% & $100 \%$ & $100 \%$ \\
Average Area of 6 injections & 1329442 & 1086961 \\
RSD\% & 1.85 & 1.83 \\
Asymmetry (USP) & 1.15 & 1.08 \\
Resolution & N.A & 5.24 \\
Theoretical Plates (USP) & 14272 & 15427 \\
Initial Retention time & 3.183 & 3.773 \\
Final Retention time & 3.184 & 3.788 \\
\hline
\end{tabular}

\section{Method Precision Sample Test Preparation}

Six sample solutions were prepared for the same homogenous sample solution preparation and injected thrice for each sample to calculate their RSD \% and assay \% the data obtained in table (3).

Table 3: Method Precision Test Results.

\begin{tabular}{ccc}
\hline & \multicolumn{2}{c}{ Assay \% } \\
\hline Sample \# & Esomeprazole & Tadalafil \\
\hline $\mathbf{1}$ & 101.8 & 101.4 \\
$\mathbf{2}$ & 99.2 & 99.9 \\
$\mathbf{3}$ & 102 & 101.2 \\
$\mathbf{4}$ & 99.4 & 99.7 \\
$\mathbf{5}$ & 99.9 & 101.9 \\
$\mathbf{6}$ & 98.6 & 101.3 \\
Average & 100.17 & 100.9 \\
RSD\% & 1.44 & 0.88 \\
\hline
\end{tabular}

\section{Intermediate Precision Sample Test Preparation}

For the same six sample preparation of method precision are injected three times for each sample but in different time and analyst, RSD \% and assay\% were calculated, data is shown in table (4).

Table 4: Results of Intermediate Precision.

\begin{tabular}{ccc}
\hline & \multicolumn{3}{c}{ Assay\% } \\
\hline Sample \# & Esomeprazole & Tadalafil \\
$\mathbf{1}$ & 101.5 & 101.8 \\
$\mathbf{2}$ & 100.6 & 100.8 \\
$\mathbf{3}$ & 101.1 & 101.3 \\
$\mathbf{4}$ & 101.1 & 101.4 \\
$\mathbf{5}$ & 98.3 & 98.5 \\
$\mathbf{6}$ & 100 & 100.2 \\
Average & 100.43 & 100.67 \\
RSD \% & 1.16 & 1.19 \\
Average & 100.3 & 100.79 \\
RSD \% & 1.26 & 1.00 \\
\hline
\end{tabular}

\section{Linearity Sample Test Preparation}

Five standard samples $(50 \%, 80 \%, 100 \%, 120 \%$ and $150 \%$ ) of the standard sample concentration for esomeprazole and tadalafil were prepared to evaluate the linearity. $50 \%$ concentration level yield from dissolving $30 \mathrm{mg}$ esomeprazole and $20 \mathrm{mg}$ tadalafil in $50 \mathrm{ml}$ solvent of mobile phase. $80 \%$ concentration level yields from dissolving $48 \mathrm{mg}$ esomeprazole and $32 \mathrm{mg}$ tadalafil in $50 \mathrm{ml}$ solvent of mobile phase. $100 \%$ conc. Level yields from dissolving $60 \mathrm{mg}$ esomeprazole and $40 \mathrm{mg}$ tadalafil in $50 \mathrm{ml}$ solvent of mobile phase. $120 \%$ concentration level yields from dissolving $72 \mathrm{mg}$ esomeprazole and $48 \mathrm{mg}$ tadalafil in $50 \mathrm{ml}$ solvent of mobile phase. $150 \%$ concentration level yields from dissolving $90 \mathrm{mg}$ esomeprazole and $60 \mathrm{mg}$ tadalafil in $50 \mathrm{ml}$ solvent of mobile phase. Triple injections analysis of each sample, a linear analysis was done on average peak areas versus the concentration of level studied. The results for esomeprazole and tadalafil are shown in table (5).

Table 5: Results of Linearity of Esomeprazole and Tadalafil (for linearity plot refer to figure 6 and 7)

\begin{tabular}{lcl}
\hline & Esomeprazole & \\
\hline Concentration \% & Average Area & RSD \% \\
\hline $50(57.8 \mathrm{mg} / \mathrm{L})$ & 661967 & 1.23 \\
$80(86.48 \mathrm{mg} / \mathrm{L})$ & 966758 & 1.21 \\
$100(115.6 \mathrm{mg} / \mathrm{L})$ & 1299576 & 1.05 \\
$120(142.72 \mathrm{mg} / \mathrm{L})$ & 1605229 & 1.16 \\
$150(173.4 \mathrm{mg} / \mathrm{L})$ & 1934556 & 1.13 \\
\hline & Tadalafil & RSD \% \\
\hline Concentration \% & Average Area & 1.11 \\
\hline $50(36.9 \mathrm{mg} / \mathrm{L})$ & 530485 & 1.09 \\
$80(56.04 \mathrm{mg} / \mathrm{L})$ & 779603 & 1.12 \\
$100(73.8 \mathrm{mg} / \mathrm{L})$ & 1044488 & 1.25 \\
$120(88.56 \mathrm{mg} / \mathrm{L})$ & 1253386 & 0.95 \\
$150(110.7 \mathrm{mg} / \mathrm{L})$ & 1562480 & \\
\hline
\end{tabular}

\section{Accuracy Sample Test preparation}

Three samples at three different concentration levels $50 \%, 100 \%$ and $150 \%$ were prepared by dissolving it in mobile phase solution (solvent) and diluting in $50 \mathrm{ml}$ mobile phase as in sample solution preparation, in each level of concentration the injection is triplicate in comparison to standard sample solution; which is prepared also by the same way, results are shown in table (6). 
Table 6: Results of Accuracy of Esomeprazole and Tadalafil.

\begin{tabular}{lccc}
\hline \multicolumn{3}{c}{ Esomeprazole } \\
\hline Concentration \% & $\mathbf{5 0 \%}$ & $\mathbf{1 0 0} \%$ & $\mathbf{1 5 0} \%$ \\
Area & 6548275 & 1315487 & 1969204 \\
Assay \% & 99.40 & 100.36 & 100.31 \\
RSD \% & 0.34 & 0.16 & 0.04 \\
\hline & \multicolumn{2}{c}{ Tadalafil } \\
\hline Concentration \% & $\mathbf{5 0 \%}$ & $\mathbf{1 0 0} \%$ & $\mathbf{1 5 0 \%}$ \\
Average Area & 536000 & 1131115 & 1571804 \\
Assay \% & 101.81 & 101.68 & 100.18 \\
RSD\% & 0.57 & 1.51 & 0.27 \\
\hline
\end{tabular}

\section{Stability of Analytical Solution Test Preparation}

The stability of standard solution was evaluated at room temperature $25{ }^{\circ} \mathrm{C}$ and fridge temperature $4{ }^{\circ} \mathrm{C}$ stored for 24 and 48 hours. The results obtained were compared with fresh standard solution $100 \%$ according to (ICH) guideline.

For each sample preparation the concentration is 120 $\mu \mathrm{g} / \mathrm{mL}$ of Esomeprazole and $80 \mu \mathrm{g} / \mathrm{mL}$ Tadalafil dissolved in mobile phase solvent. The stability results are shown for Esomeprazole and Tadalafil in table (7) respectively for 24 and 48 hours.

Table 7: Results of Solution stability of both standard and sample of Eomeprazole and Tadalafil after 24 and $48 \mathrm{hrs}$

\begin{tabular}{|c|c|c|c|c|}
\hline \multirow{2}{*}{$\begin{array}{c}\begin{array}{c}\text { Time and } \\
\text { Temperatures }\end{array} \\
\begin{array}{c}\text { Standard } \\
\text { solution }\end{array}\end{array}$} & \multicolumn{2}{|c|}{$\begin{array}{c}\text { Average AUCs of } \\
\text { Esomeprazole. } \\
(120 \mu \mathrm{g} / \mathrm{mL})\end{array}$} & \multicolumn{2}{|c|}{ Assay \% } \\
\hline & Nexium $^{\circledR}$ & Pumpinox $^{\circledR}$ & Nexium $^{\circledR}$ & Pumpinox $^{\circledR}$ \\
\hline 24 hrs at $25^{\circ} \mathrm{C}$ & 1499391 & 1688018 & 98.77 & 99.6 \\
\hline $24 \mathrm{hrs}$ at $4{ }^{\circ} \mathrm{C}$ & 1507655 & 1688511 & 98.23 & 99.55 \\
\hline $48 \mathrm{hrs}$ in $25^{\circ} \mathrm{C}$ & 1510442 & 1696718 & 98.05 & 99.07 \\
\hline $48 \mathrm{hrs}$ in $4^{\circ} \mathrm{C}$ & 1512311 & 1687765 & 98 & 99.6 \\
\hline \multirow{2}{*}{$\begin{array}{c}\text { Standard } \\
\text { solution }\end{array}$} & \multicolumn{2}{|c|}{$\begin{array}{l}\text { Average of AUCs of } \\
\text { Tadalafil }(80 \mu \mathrm{g} / \mathrm{mL})\end{array}$} & \multicolumn{2}{|c|}{ Assay \% } \\
\hline & Cialis $^{(\circledR)}$ & Adam $^{(B)}$ & Cialis $^{\left({ }^{(}\right)}$ & Adam $^{(\circledR)}$ \\
\hline $24 \mathrm{hrs}$ at $25^{\circ} \mathrm{C}$ & 980739 & 1420564 & 98.93 & 100.06 \\
\hline $24 \mathrm{hrs}$ at $4{ }^{\circ} \mathrm{C}$ & 1003364 & 1420449 & 101.2 & 100.5 \\
\hline $48 \mathrm{hrs}$ in $25^{\circ} \mathrm{C}$ & 1008276 & 1426234 & 101.7 & 99.67 \\
\hline $48 \mathrm{hrs}$ in $4{ }^{\circ} \mathrm{C}$ & 1002576 & 1419129 & 101.13 & 100.17 \\
\hline
\end{tabular}

\section{Robustness Test Preparation}

Robustness was performed using sample solutions prepared as in sample solution preparation, in brief; about $860 \mathrm{mg}$ of Nexium $^{\circledR}$ equals to $60 \mathrm{mg}$ of the esomeprazole and $718 \mathrm{mg}$ Cialis $^{\circledR}$ equals to $40 \mathrm{mg}$ of the tadalafil were taken in $50 \mathrm{~mL}$ of mobile phase and diluted 10 times by taking $5 \mathrm{~mL}$ of each solution in another $50 \mathrm{~mL}$ of the mobile phase to obtaine concentrations of about 120 and $80 \mu \mathrm{g} / \mathrm{mL}$ esomeprazole and tadalafil, respectively.

Standard solution preparations were prepared by dissolving 60 of esomeprazole and $40 \mathrm{mg}$ of tadalafil using highly pure material (> 99.7\%) in $50.0 \mathrm{~mL}$ volumetric flask of mobile phase. Then $5.0 \mathrm{~mL}$ from each stock solution were diluted into $50.0 \mathrm{~mL}$ mobile phase. Concentrations of about 120 and 80 $\mu \mathrm{g} / \mathrm{mL}$ were obtained, for esomeprazole and tadalafil respectively. Samples from both samples and standard preparations were injected in triplicates using the following changes in the method conditions separately.
Robustness Regarding Wavelength (+3 and -3$)$

Detector wavelength was changed using a UV detection limit of 282 and $288 \mathrm{~nm}$ separately; the results obtained are shown in table (8).

Table 8: Results of Robustness Regarding Wavelength $( \pm 3)$.

\begin{tabular}{|c|c|c|c|c|}
\hline Parameters & \multicolumn{2}{|c|}{ Wavelength $(285 \mathrm{~nm})$} & \multicolumn{2}{|c|}{ Wavelength $(288 \mathrm{~nm})$} \\
\hline Material & Esomeprazole & Tadalafil & Esomeprazole & Tadalafil \\
\hline Average Area & 1424809 & 1155465 & 1631833 & 1140995 \\
\hline RSD \% & 0.67 & 0.69 & 0.26 & 0.22 \\
\hline Theoretical plates & 3779 & 4354 & 3807 & 4372 \\
\hline Asymmetry (USP) & 1.16 & 1.10 & 1.15 & 1.09 \\
\hline Resolution (USP) & N.A & 2.73 & N.A & 2.73 \\
\hline Parameters & \multicolumn{2}{|c|}{ Wavelength $(285 \mathrm{~nm})$} & \multicolumn{2}{|c|}{ Wavelength $(282 \mathrm{~nm})$} \\
\hline Material & Esomeprazole & Tadalafil & Material Esc & meprazole \\
\hline Average Area & 1299576 & 1044488 & 1317245 & 1182444 \\
\hline RSD \% & 0.28 & 1.19 & 0.86 & 0.68 \\
\hline Theoretical plates & 9016 & 9907 & 3851 & 4447 \\
\hline Asymmetry (USP) & 1.06 & 1.027 & 1.15 & 1.09 \\
\hline Resolution (USP) & N.A & 4.18 & N.A & 2.74 \\
\hline
\end{tabular}

\section{Robustness Regarding $\mathrm{pH}$ Changing (+0.2 and -0.2)}

A mobile phase of a mixture of $60 \%$ acetonitrile: $40 \%$ buffer was prepared then separated into two parts; the $\mathrm{pH}$ of the first part was adjusted to be 5.8 and the second part 6.2 then used for estimation of the drugs separately. The data obtained are shown in table (9).

Table 9: Robustness regarding $\mathrm{pH} \pm 0.2$

\begin{tabular}{|c|c|c|c|c|}
\hline Parameters & \multicolumn{2}{|c|}{ pH 6.00 } & \multicolumn{2}{|c|}{ pH 6.20} \\
\hline Material & Esomeprazole & Tadalafil & Esomeprazole & Tadalafil \\
\hline Average Area & 1299576 & 1044488 & 1388191 & 1150011 \\
\hline RSD \% & 0.28 & 1.19 & 0.26 & 0.76 \\
\hline $\begin{array}{l}\text { Theoretical } \\
\text { plates }\end{array}$ & 9017 & 9907 & 4395 & 5002 \\
\hline Asymmetry & 1.06 & 1.03 & 1.10 & 1.03 \\
\hline Resolution & N.A & 4.15 & N.A & 2.89 \\
\hline Parameters & \multicolumn{2}{|c|}{ pH 6.00} & \multicolumn{2}{|c|}{ pH 5.80} \\
\hline Material & Esomeprazole & Tadalafil & Esomeprazole & Tadalafil \\
\hline Average Area & 1299576 & 1044488 & 1393302 & 1152615 \\
\hline RSD \% & 0.28 & 1.19 & 0.5 & 0.55 \\
\hline $\begin{array}{l}\text { Theoretical } \\
\text { plates }\end{array}$ & 9017 & 9907 & 4279 & 4910 \\
\hline Asymmetry & 1.06 & 1.03 & 1.10 & 1.02 \\
\hline Resolution & N.A & 4.15 & N.A & 2.91 \\
\hline
\end{tabular}

Table 10: Robustness regarding organic modified in mobile Phase $( \pm 5 \%)$.

\begin{tabular}{|c|c|c|c|c|}
\hline Parameters & \multicolumn{2}{|c|}{ Mobile phase (60:40) } & \multicolumn{2}{|c|}{ Mobile phase (65:35) } \\
\hline Material & Esomeprazole & Tadalafil & Esomeprazole & Tadalafil \\
\hline Average Area & 1299576 & 1044488 & 1311356 & 1010608 \\
\hline RSD \% & 0.28 & 1.19 & 0.21 & 1.08 \\
\hline $\begin{array}{l}\text { Theoretical } \\
\text { plates }\end{array}$ & 9017 & 9907 & 6240 & 7191 \\
\hline Asymmetry & 1.06 & 1.03 & 0.94 & 0.92 \\
\hline Resolution & N.A & 4.15 & N.A & 4.56 \\
\hline Parameters & \multicolumn{2}{|c|}{ Mobile phase (60:40) } & \multicolumn{2}{|c|}{ Mobile phase (55:45) } \\
\hline Material & Esomeprazole & Tadalafil & Esomeprazole & Tadalafil \\
\hline $\begin{array}{l}\text { Average } \\
\text { Area }\end{array}$ & 1299576 & 1044488 & 1246202 & 928806 \\
\hline RSD \% & 0.28 & 1.19 & 1.58 & 1.89 \\
\hline $\begin{array}{l}\text { Theoretical } \\
\text { plates }\end{array}$ & 9017 & 9907 & 4973 & 5962 \\
\hline Asymmetry & 1.06 & 1.03 & 0.92 & 0.93 \\
\hline Resolution & N.A & 4.15 & N.A & 2.27 \\
\hline
\end{tabular}




\section{Robustness Regarding Organic Modified Composition (+5 \% and} $-5 \%)$

Two mobile phases were prepared; first one prepared using a mixture of $65 \%$ acetonitrile: $35 \%$ buffer and second using $55 \%$ acetonitrile: $45 \%$ buffer, then $\mathrm{pH}$ was adjusted to be 6.0 . The mobile phases were used separately applying the same chromatographic conditions. The data obtained are shown in table (10).

\section{Specificity Test Preparation}

The specificity of the developed HPLC method for esomeprazole and tadalafil was determined in the presence of both drugs and the placebo contents.

Two commercial batches of the finished products found in market used as test formulation in this test. One local and one international drug were used. Each was dissolved in mobile phase and injected in the system. In addition raw materials and placebo contents used as reference formulation were dissolved in mobile phase and injected in the system; the data obtained is shown in table (11).

Table 11: Recovery $\%$ of test and reference formulation

\begin{tabular}{lcc}
\hline Material & Esomeprazole & Tadalafil \\
\hline Test formulation & 98.77 & 98.93 \\
Reference formulation & 99.6 & 101.2 \\
\hline
\end{tabular}

\section{Force Degradation Test Preparation}

Raw materials of both drugs (esomeprazole and tadalafil) were exposed to5 $\mathrm{mL}$ of $1 \mathrm{M} \mathrm{HCl}$ at room temperature for 60 minutes and then dissolved in mobile phase. Also same procedure was done by using $1 \mathrm{M} \mathrm{NaOH}$. Samples then injected for analysis of stability. Results are presented in table (12).

\section{RESULTS AND DISCUSSIONS}

\section{System Precision}

The purpose of system precision is to find the degree of agreement between individual test results when the procedure is applied repeatedly to multiple injections (6 injections) of the same homogenous sample. Precision was calculated as repeatability of both drugs and the method was precise with \% RSD (n=6)) 1.85 and 1.83 for esomeprazole and tadalafil respectively, (Table (2) and figure (3)) and this results indicates good system suitability because according to USP the method consider precise if \% RSD is below $2 \%$.

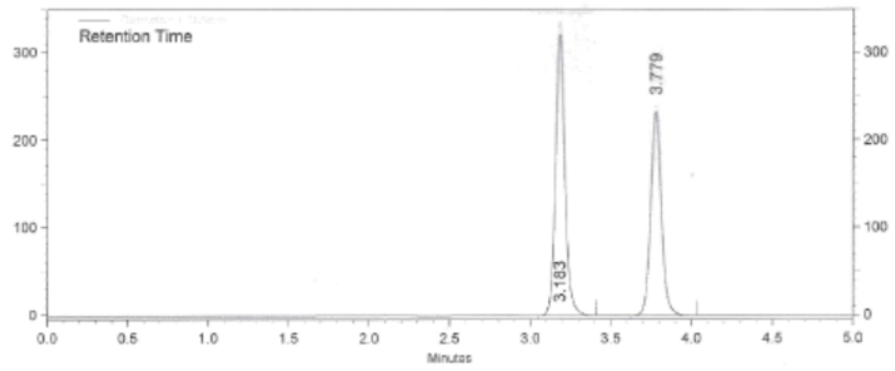

Fig. 3: Chromatogram of system suitability.

\section{Method Precision}

The precision of the method was performed by analyzing six preparations of each drug (esomeprazole and tadalafil) at the target concentration, data obtained is shown in table (3) and the chromatogram of method precision test is shown in figure (4). The data presented data shows that the mean value of assay $\%$ are between $(98-102 \%)$ and the relative standard deviation is below $2 \%$, both of them are within the accepted range (according to USP), therefore the presented method is precise. Also, the chromatogram (figure 4) shows a good separation of the two drugs with no overlapping between the peaks and this indicates a precise method.

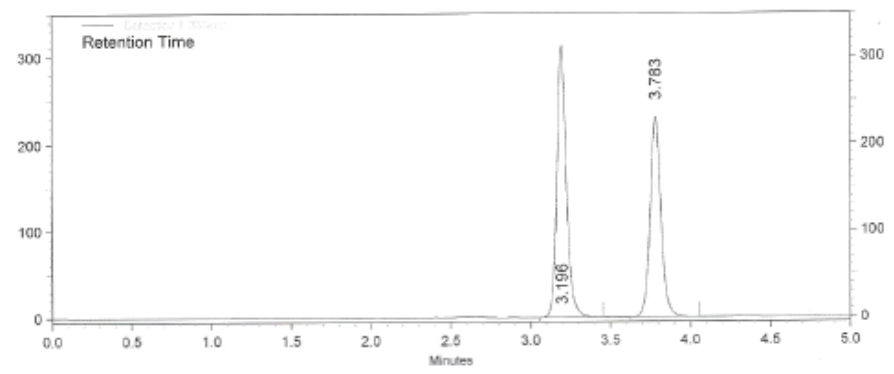

Fig. 4: Chromatogram of method precision.

\section{Intermediate Precision}

It is obtained by running composite samples in two different days using different equipment. In the first day, the six prepared samples were analyzed using the same chromatographic conditions and the data (Assay \%, RSD \%) were obtained. Assay value obtained was within range 98\% - 102\% (Table 4).The chromatogram shows a good separation of the two drugs (esomeprazole and tadalafil) with no overlapping between the peaks and this indicates a good intermediate precision (Figure 5).

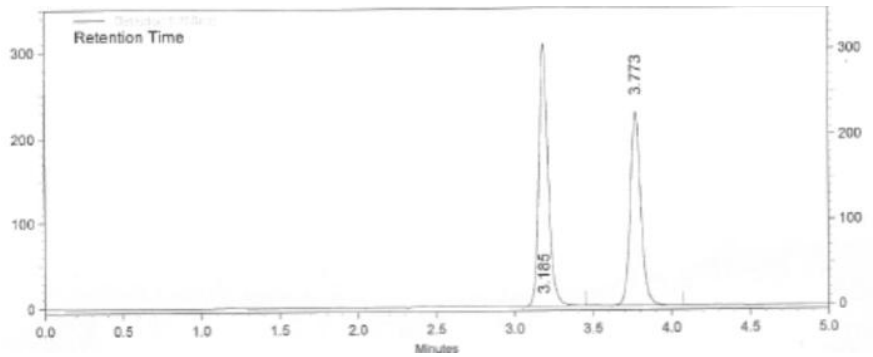

Fig. 5: Chromatogram of intermediate precision.

\section{Linearity}

Linearity was evaluated by using a series of standard concentrations $(50 \%, 80 \%, 100 \%, 120 \%$ and $150 \%)$ of each drug prepared (refer to section 2.12. Linearity Sample Test Preparation).Then triple analysis for each sample was done, a linear analysis was observed on average peak areas versus the concentrations of level studied. Also LOD and LOQ values were measured for both drugs. The results for esomeprazole and tadalafil are listed in table (5).

The calibration curve of peak area versus concentration $\%$ for esomeprazole is shown in figure (6). The R $2=0.9998$, so the 
equation gives a good linearity for esomeprazole, within stated limit to observe the linearity validation method. Tadalafil is analyzed in the same range and the observed data (AUCs and RSD $\%$ ) are listed in table (5). Calibration curve of average areas of tadalafil versus the conc. \% gives the linear curve of tadalafil shown in figure (7).

Both drugs, esomeprazole and tadalafil R2 values are within the accepted range, and the calibration curve equation gave a good linearity curve for both of them coupled with shown chromatograms for each level indicate the linearity test is validate.

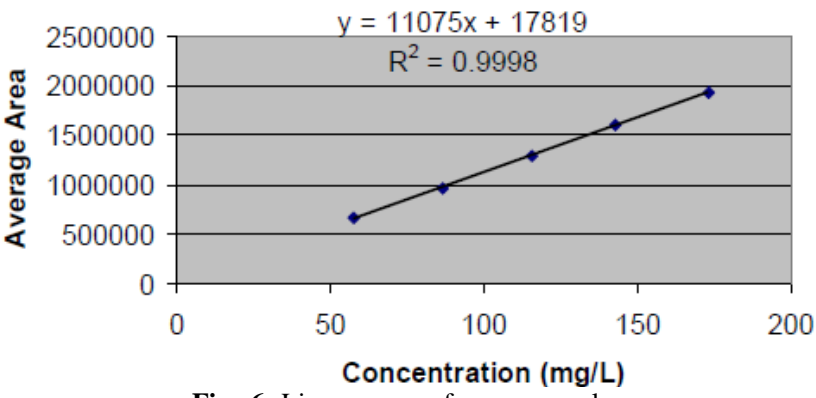

Fig. 6: Linear curve of esomeprazole.

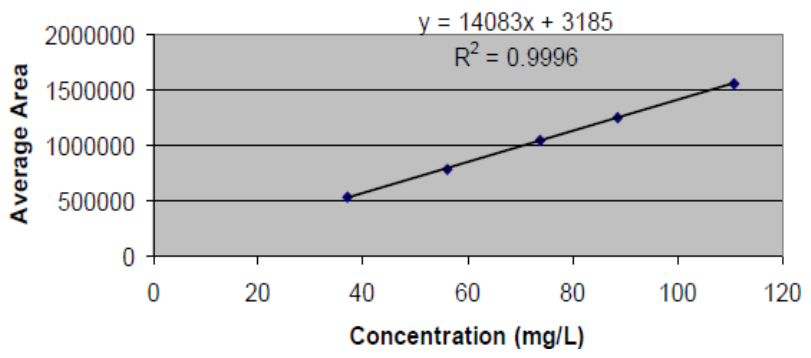

Fig. 7: Linear curve of tadalafil.

\section{Accuracy}

In order to estimate the accuracy, samples at three different concentrations $50 \%, 100 \%$, and $150 \%$ were analyzed, in each concentration injected three times in comparison to standard sample (Tables 6$)$. The $\%$ of recovery equation: \% Accuracy= (recovered amount / actual amount) X 100. The accepted limits of recovery are $98 \%$ - $102 \%$ according to USP.

The data indicating a good recovery value for both drugs; all data observed are within $98 \%-102 \%$ according to USP. So, it has been noted from these results that both drugs show a validate accuracy test results.

\section{Stability of Analytical Solution}

The stability of solution should be evaluated by storing the solution under known concentration at room temperature and fridge for 24 and 48 hours compared to fresh standard solution. A concentration of $120 \mu \mathrm{g} / \mathrm{mL}$ of esomeprazole and $80 \mu \mathrm{g} / \mathrm{mL}$ of tadalafil were analyzed against standard solution. The stability results within stated limit of range 98\% - 102\% in 24 and 48 hrours are listed in table (7). The given results show that the assay percent under all tested conditions are within the accepted USP range $98 \%$ - $102 \%$. Such results indicate that both drugs; esomeprazole and tadalafil are stable under the test conditions.

\section{Robustness}

This test is applied to improve the method robustness by making variations in procedure parameters within certain limits without changing in the obtained results. In general, it's done by varying procedure parameters and observing what effect it produces on the analyte analysis. Robustness was performed using solutions prepared in a similar fashion as system or method precision, the number of replicates (typically 3 ), and was evaluated based on system suitability parameters or on recovered amounts, both compared to data generated using the original method. The following changes were done separately:

\section{Robustness Regarding Wavelength ( \pm 3)}

Slight variation in wavelength had been done to the analytical method in order to evaluate and measure the capacity of the method to remain unaffected by small variations. A concentration at level $100 \%$ was analyzed at each level against a standard solution. The based wavelength was $285 \mathrm{~nm}$, and changed by $\pm 3 \mathrm{~nm}$ wavelength. The analysis results (Table 8 ) showed a slightly variation in AUCs of esomeprazole and tadalafil, but RSD\% values remain within the accepted range $(<2 \%)$ and hence the results are validate and the method is robust.

\section{Robustness Regarding pH changing $( \pm 0.2)$}

The main $\mathrm{pH}$ used in this method was 6.0and the changing made by $( \pm 0.2)$ units, and the results obtained are shown in tables (9). These results indicate that the analytical method is robust for both drugs; esomeprazole and tadalafil.

\section{Robustness Regarding ( \pm 5\%) Organic Modified Composition}

Slight variations in composition of mobile phase have been made to the analytical method to evaluate and measure the capacity of the method to remain unaffected by small variation. At level $100 \%$ analytical concentration is analyzed against standard solution. The results show that the $\%$ RSD $<2 \%$ and gave indication that the method is robust.The results are listed in tables (10).

\section{Specificity}

It is important to study the selectivity of the method to determine the capacity of the method to measure accurately and specifically in the presence of active ingredients, placebo and other ingredient. A standard, sample, solvent and placebo solutions were injected into the column according to the parameters stated under the developed method. It was found that there is no interference between the analyte and both the solvent and placebo.

\section{Placebo analysis}

A placebo solution prepared in the laboratory based on the most common and available excipients. They are Avicel 65\%, Mg-stearate 5\%, Lactose 15\%, and Starch 15\%, by weighing 700 $\mathrm{mg}$ in $50 \mathrm{~mL}$ of mobile phase as solvent. Then injected three times (analyzed) and no interference between the analyte and both of solvent and placebo was observed with respect to target analyte no interference of blank and placebo solutions. 
In addition, selectivity test includes the analysis of drugs in the pharmaceutical formulation, comparing between the results of analysis of local Jordanian manufactured drugs formulations with some international foreign formulations, such as nexium ${ }^{\circledR}$ for esomeprazole and cialis ${ }^{\circledR}$ for tadalafil and results of local products such as pumpinox ${ }^{\circledR}$ tablets for esomeprazole and Adam ${ }^{\circledR}$ for tadalafil (test formulation) with results from the active material that we used (Reference formulation). These results are summarized in table (11) showed that the recovery \% for test and reference formulations are within the accepted range, and from all the chromatograms we conclude that the method is selective.

\section{Force degradation}

Forced degradation studies were also performed on esomeprazole and tadalafil to provide an indication of the stabilityindicating property and specificity of the proposed method. The stress conditions employed for the degradation study included the following: both drugs were exposed to $1 \mathrm{M}$ of $\mathrm{HCL}$ and $\mathrm{NaOH}$ at room temperature for $60 \mathrm{~min}$. Both Esomeprazole and Tadalafil showed no significant sensitivity towards the treatment of $1 \mathrm{M} \mathrm{HCl}$ and $1 \mathrm{M} \mathrm{NaOH}$. Data are represented in table (12)

Table 12: The purity angle and purity threshold for the standard, active ingredient and placebo solution.

\begin{tabular}{lcc}
\hline \multicolumn{1}{c}{ Sample name } & $\begin{array}{c}\text { Purity of } \\
\text { Esomeprasole (\%) }\end{array}$ & $\begin{array}{c}\text { Purity of } \\
\text { Tadalafil (\%) }\end{array}$ \\
\hline Standard at normal condition & 99.91 & 99.91 \\
Sample at normal condition & 99.92 & 99.90 \\
Standard with 1M HCl & 99.92 & 99.87 \\
Sample with 1M HCl & 99.94 & 99.32 \\
Standard with 1M NaOH & 99.98 & 99.45 \\
Sample with 1M NaOH & 99.94 & 99.85 \\
\hline
\end{tabular}

Table 13: ANOVA single factor of Esomeprazole for Variation of day and equipment.

\begin{tabular}{|c|c|c|c|c|c|c|}
\hline \multicolumn{7}{|c|}{ Analysis of Variance (One-Way) Summary } \\
\hline Groups & $\overline{\mathrm{E}}$ & \multicolumn{2}{|c|}{ Sum Mean } & \multicolumn{2}{|l|}{ Variance } & \\
\hline$\overline{\text { Day } 1}$ & 6 & 601 & 100.17 & 2.090667 & & \\
\hline Day 2 & 6 & 606.1 & 101.02 & 0.413667 & & \\
\hline ANOVA & & & & & & \\
\hline Variation & SS & Df & MS & $\mathbf{F}$ & p-level & F crit \\
\hline Between Groups & 2.17 & 1 & 2.168 & 1.731 & 0.218 & 4.965 \\
\hline Within Groups & 12.52 & 10 & 1.252 & & & \\
\hline Total & 14.69 & 11 & & & & \\
\hline
\end{tabular}

Table 14: ANOVA single of Tadalafil for Variation of day and equipment.

\begin{tabular}{|c|c|c|c|c|c|c|}
\hline \multicolumn{7}{|c|}{ Analysis of Variance (One-Way) Summary } \\
\hline \multirow{2}{*}{$\begin{array}{l}\text { Groups } \\
\text { Day } 1\end{array}$} & \multirow{2}{*}{ 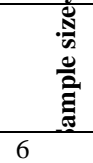 } & \multicolumn{2}{|c|}{ Sum Mean } & \multicolumn{2}{|c|}{ Variance } & \\
\hline & & 6 & 605.4 & 100.9 & & \\
\hline Day 2 & 6 & 603 & 100.5 & 1.144 & & \\
\hline ANOVA & & & & & & \\
\hline Variation & SS & Df & MS & $\mathbf{F}$ & p-level & F crit \\
\hline Between Groups & 0.48 & 1 & 0.481 & 0.497 & 0.497 & 4.965 \\
\hline Within Groups & 9.66 & 10 & 0.966 & & & \\
\hline Total & 10.14 & 11 & & & & \\
\hline
\end{tabular}

ANOVA Single Factor test for Esomeprazole Validation Data Method Reproducibility

Variation of Analysis

ANOVA statistical method is used to analyze the differences between group means and their associated procedure. The results (Table 13, 14) showed that, $\mathrm{F}$ value is less than $\mathrm{F}$ critical and p-level value was less than 1 so the data obtained is statistically significant.

\section{CONCLUSION}

The proposed HPLC method provide simple, specific, precise, accurate, and reproducible quantitative analysis for simultaneous analysis of esomeprazole and tadalafil in pharmaceutical formulation. The method was validated as per ICH guidelines in terms of linearity, accuracy, precision, limits of detection (LOD) and quantification (LOQ), robustness, and reproducibility. The proposed method can be used for routine analysis and quality control assay of esomeprazole and tadalafil in pharmaceutical formulation. We believe that the HPLC method presented by this work has a lot of merits over the earlier reported methods; it doesn't need internal standard making it more cost effective and simple to apply. Also, we recommend for the future bioanalytical methods to utilize apply this method for estimation of esomeprazole and tadalafil in various biological matrixes with little or no modification.

\section{ACKNOWLEDGMENT}

The authors are thankful Faculty of Pharmacy and Medical Sciences - University of Petra and for assistance and support of this work.

\section{CONFLICT OF INTERESTS}

Authors declared none

\section{REFERENCES}

Abu Dayyih W, Al saadi N, Hamad M, Mallah E., Matalka K, Arafa T. Development and validation of hplc method for some azoles in pharmaceutical preparation. Int. J. Pharm. Sci. Res, 2012; 3: 3686- 3692.

Abu Dayyih W, Alsaid S, Hamad M, Al Akayleh F, Mallah E. Development and validation of a reversed phase hplc method for simultaneous estimation of some prills in drug forms. Int J Pharm Pharm Sci, 2013; 5: 203-213.

Allen DS, Wilson SK, Knapp PM. The efficacy and safety of tadalafil in United States and Puerto Rican men with erectile dysfunction. J Urol, 2004; 172: 652-627.

Daugan A, Grondin P, Ruault C, Le Monnier de Gouville AC, Coste H, Kirilovsky J, Hyafil F, Labaudinière R. The discovery of tadalafil: a novel and highly selective PDE5 inhibitor. J Med Chem, 2003; 9:102- 110 .

Dilip G, Maheshwari A, Priti D. Simultaneous Estimation of Esomeprazole and Domperidone in Combined Dosage form by HPLC. Int. J. Appl. Sci. Eng, 2011; 1:1-8

Farthing A, Farthing D, Koka S, Larus T, Fakhry I, Xi L, Kukreja R, Sica D, Geh T. A simple and sensitive HPLC fluorescence method for determination of tadalafil in mouse plasma. $\mathrm{J}$ of Chrom B, 2010; 878(28): 2891-2895. 
Fischbach L, Evans EL. Meta-analysis: the effect of antibiotic resistance status on the efficacy of triple and quadruple first-line therapies for Helicobacter pylori. Aliment Pharmacol Ther, 2007; 26: 343-348.

Hultman I, Stenhoff H, Liljeblad M. Determination of esomeprazole and its two metabolities in human, rat and dog plasma by liquid chromatography with tandem mass spectrometry. J Chrom B. 2007; 848: 317-322.

Jain D.R, Jain N, Chardem R, Jain N. The RP-HPLC method for simultaneous estimation of esomeprazole and naproxen in binary combination. Pharm. Methods, 2011; 20: 10.

Johnson DA. Esomeprazole: a clinical review. Expert Opin Pharmacother, 2003; 4(2): 253-264.

Kamepalli Sujana D, Sankar G, Abbulu K, Souri O. New Validated RP-HPLC method for the Determination of Tadalafil in Bulk and Dosage form. Int J Pharma W Res, 2012; Mar-June.

Kumar S.T., Kumar B.K., Kumar A. S., Mohan M., Nanda S.S., Venkateshwar Rao P. Development and Validation of RP-HPLC Method for Simultaneous Estimation of Esomeprazole and Domperidone in Pharmaceutical Dosage Form. J of Pharm Res, 2011; 4(11):4097-4099.

Lind T, Rydberg L, Kyleback A, Jonsson A, Andersson T and Hasselgren G. Esomeprazole provides improved acid control vs. omeprazole in patients with symptoms of gastrooesophageal reflux disease. Aliment Pharmacol Ther, 2000; 14: 861-867.

McColl K.E, el-Omar E, Gillen D. Interactions between $H$. pylori infection, gastric acid secretion and anti-secretory therapy. Br Med Bull, 1998; 54: 121-138.

Nagaraju V, Prasad S, Sivanaga Kumar A, Sudheer Kumar N, Roja D, Hareesha P.Determination of esomeprazole in tablet formulations by reverse phase hplc Int. J.A.PS.BMS, 2012; 1(1): 25-31

Nalwade S.U, Reddy V.R, Rao D.D, Morisetti N.K. A validated stability indicating ultra-performance liquid chromatographic method for determination of impurities in esomeprazole magnesium gastro resistant tablets. J. Pharm. Biomed, 2012; 57: 109-114.

Onal A, Oztunç A. Development and validation of high performance liquid chromatographic method for the determination of esomeprazole in tablets. J. Food Drug Anal, 2006; 14(1): 12-18.
Patil Shamkant S, Dhabale Pandurang N, Kuchekar Bhanudas S. Development and Statistical Validation of Spectrophotometric Method for Estimation of Esomeprazole in Tablet Dosage Form. Asia J. Res Chem, 2009; 2(2): April.-June.

Rajpar C, Akhtar J, Khandhar A. Pharmatutor. (2012): 1:1-5

Rafferty J.L, Sun L, Siepmann J.I, Schure M.R. Fluid Phase Equilib, 2010; 290: 25-35.

Samala A, Pawar S, Manala S, Chada M, Nageshwar M.Pepsins, peptic activity, and peptic inhibitors. J. Chem. Pharm. Res, 2013; 5(4): 315-318.

Scott LJ, Dunn C.J, Mallarkey G and Sharpe M. Esomeprazole: a review of its use in the management of acid-related disorders. Drugs, 2002 62(10): 1503-1538.

Snyder L.R, Kirkland J.J, Dolan J.W. Introduction to modern liquid chromatography; John Wiley \& Sons, Inc. 2010; 912.

Taverniers I, Loose M, Bockstaele V.E. Trends in quality in the analytical laboratory, II: analytical method validation and quality assurance. Trend Anal Chem, 2004; 23: 535-552.

The United States pharmacopeia (USP) and the National Formulary (NF). The Official Compendia of Standards, 2006; 29: 1225.

\section{How to cite this article:}

Hamad M, Al-Sharqawi A, Dayyih WA, Mallah E, Arafat T. Simultaneous estimation of Esomeprazole and Tadalafil in pharmaceutical formulationsusing High Performance Liquid Chromatography. J App Pharm Sci, 2016; 6 (04): 052-059. 